\title{
A DOR NO COTIDIANO DE CUIDADORES E CRIANÇAS COM ANEMIA FALCIFORME ${ }^{1}$
}

\author{
Tatiane Lebre Dias* \\ Universidade Federal de Mato Grosso, \\ Cuiabá, MT, Brasil; \\ Universidade do Estado de Mato Grosso, \\ Cuiabá, MT, Brasil. \\ Christyne Gomes Toledo de Oliveira \\ Faculdade Católica Salesiana do Espírito Santo \\ Vitória, ES, Brasil. \\ Sônia Regina Fiorim Enumo \\ Pontifícia Universidade Católica de Campinas, \\ Campinas, SP, Brasil. \\ Universidade Federal do Espírito Santo, \\ Vitória, ES, Brasil. \\ Kely Maria Pereira de Paula \\ Universidade Federal do Espírito Santo, \\ Vitória, ES, Brasil.
}

1 Estudo derivado de Projeto Integrado de Pesquisa Estratégias de enfrentamento: Estudos em contextos de risco ao desenvolvimento (Edital MCT/CNPq 14/2009 02-2006; Proc. n. 481483/2009-8). Apoio financeiro: Conselho Nacional de Desenvolvimento Cientíico e Tecnológico (CNPq) - Edital MCT/CNPq 14/2009 02-2006; Proc. n. 481483/2009-8, Fundação de Amparo à Pesquisa do Estado de Mato Grosso (FAPEMAT) - Edital Universal № 006/2010, Fundação de Amparo à Pesquisa do Espírito Santo (FAPES), Faculdade Católica Salesiana do Espírito Santo (FCSES) - Edital de Bolsa de Capacitação Docente - 2011.

Agradecimentos: Gustavo Barros Diniz (UFES- Bolsista PIBIC/UFES/CNPq), Felipe Douglas Pereira França (UFMT - Bolsista BIC/

FAPEMAT), Thayane de Almeida Ferreira (UFMT - Bolsista VIC/UFMT).

* Endereço para correspondência: tatianelebre@gmail.com 
Resumo: As crises de dor crônica ou aguda, de diferente intensidade e recorrência imprevisível, são um dos sintomas mais frequentes na Anemia Falciforme (AF) e tendem a afetar a qualidade de vida dos portadores da doença. Este estudo procurou descrever e comparar a percepção do episódio doloroso da AF entre crianças e seus cuidadores. Participaram 27 pares de cuidadorcriança, sendo 11 pares formados por crianças atendidas no Ambulatório de Pediatria do Hospital Universitário Cassiano Antônio de Moraes de Vitória/ES e 16 pares compostos por crianças que frequentavam o Hemocentro de Cuiabá/MT.Os resultados revelaram diferença na percepção de cuidador e criança sobre a caracterização da dor no que se refere ao tipo e à intensidade. As crises de dor interferem, sobretudo, nas atividades do cotidiano. A estratégia de enfrentamento mais utilizada por ambos os grupos centrou-se em pensamentos que envolveram os aspectos negativos da experiência indesejada, o que indica a necessidade de intervenção psicológica com esta população.

Palavras-chave: Anemia Falciforme. Dor. Cuidador. Crianças.

A Anemia Falciforme (AF) faz parte do grupo das hemoglobinopatias (Doença Falciforme), sendo considerada a doença crônica hereditária mais prevalente no Brasil (Diniz \& Guedes, 2003). Esta doença caracteriza-se por um tipo de hemoglobina mutante designada hemoglobina $\mathrm{S}(\mathrm{Hb}-\mathrm{S})$, que provoca a distorção (polimerização) dos eritrócitos (hemácias), fazendo-os tomar a forma de "foice" ou "meia-lua" (Brasil, 2012). Quando um indivíduo recebe o gene de um de seus genitores, sendo, portanto, heterozigoto, é portador do "traço falciforme" (Hb-AS) e não desenvolve a doença, podendo somente transmiti-la a seus filhos, diferente daquele que recebe os dois genes (Hb-SS), um de cada genitor (homozigoto) (Brasil, 2012).

De acordo com o Programa Nacional de Triagem Neonatal (PNTN), no Brasil, nascem a cada ano cerca de 3.500 crianças portadoras de AF; dessas, $20 \%$ não atingem os 5 anos de idade por complicações da doença (Brasil, 2012). Pelo fato de ser uma doença genética, a AF requer, além do diagnóstico precoce, o autocuidado e a assistência multiprofissional, de modo que o indivíduo acometido e a família sejam preparados para lidar com toda a sintomatologia dessa condição.

O quadro clínico de AF é marcado pela presença de crises dolorosas, palidez, cansaço fácil, icterícia, úlceras nas pernas e maior tendência a infecções. Segundo Silva e Marquez (2007), a dor se apresenta como a maior manifestação clínica da doença, podendo ser crônica ou aguda, desencadeada em virtude da oclusão dos pequenos vasos sanguíneos pelas hemácias falciformes. Outro sintoma clínico importante refere-se às complicações cerebrovasculares que envolvem infarto cerebral, hemorragia cerebral e alterações cognitivas e comportamentais que podem ocorrer em aproximadamente $25 \%$ dos pacientes (Sena, Vieira, \& Lyra, 2011). 
A dor é considerada um sinal vital, tendo a função de alertar e proteger o indivíduo; contudo, quando se apresenta de forma recorrente, imprevisível, com intensidade e duração variáveis, pode tornar-se prejudicial, incapacitante e angustiante, comprometendo a qualidade de vida das pessoas (Murta, 1999; Tostes, Braga, Len, \& Hilário, 2008). Nesse contexto, a identificação e o manejo de dor crônica é uma medida de proteção ao desenvolvimento, pois a experiência dolorosa é considerada um fator de risco podendo comprometer a qualidade de vida da criança e refletir nas condições psicossociais de seus familiares. De acordo com Palermo, Eccleston, Lewandowski, William e Morley (2011), crianças com dor crônica relatam altos níveis de estresse, ansiedade e depressão e, quando a dor permanece na vida adulta, provoca sintomas físicos e problemas psicológicos.

No Brasil, diversos estudos abordam episódios dolorosos na vida do portador de AF e seus reflexos no cotidiano. Graumlich et al. (2001), ao avaliarem a intensidade da dor da AF em 25 crianças (entre 7 e 12 anos de idade) e seus pais, observaram discrepância em relação à intensidade da dor percebida pelos pares, em que os pais subestimaram a dor dos filhos. Ainda em relação à percepção da dor, Correia e Linhares (2008), em revisão de literatura focando a avaliação de crianças em situação de dor, encontraram resultados semelhantes ao observarem nos pais uma tendência a subestimar a dor do filho, sobretudo em crianças em idade pré-escolar e que apresentam algum atraso cognitivo ou necessidades educativas especiais. Tostes et al. (2008), ao estudarem a crise dolorosa da AF por meio de diários e diagrama do corpo para localizar a dor, observaram que em $75 \%$ dos pacientes a dor ocorreu no abdômen, seguido de extremidades e tórax. $A$ respeito dos aspectos clínicos da dor na $A F$, segundo Lobo, Marra e Silva (2007), esta pode ser desencadeada espontaneamente ou em decorrência do frio, traumas, esforço físico, desidratação, infecções e hipóxia (Brasil, 2009).

Em termos de tratamentos que amenizem os sintomas da AF, a hidroxiuréia $(\mathrm{HU})$ tem sido utilizada como droga terapêutica que controla as complicações clínicas. A HU produz aumento dos níveis de hemoglobina fetal, reduz hemólises e crises vaso-oclusivas, diminuindo internações e dias de hospitalização, a necessidade de transfusão sanguínea, o risco de óbito e, principalmente, a frequência dos episódios de dor, proporcionando aumento na expectativa de vida dos pacientes (Bandeira, Peres \& Carvalho, 2004; Brasil, 2012). Entretanto, pesquisadores alertam para as possíveis ações genotóxicas que podem causar alterações no material genético e proporcionar sérias consequências ao organismo (Cançado, Lobo, Ângulo, Araújo, \& Jesus, 2009; Silva \& Shimauti, 2006).

Para Craychete e Wanderley (2011), a dor na criança repercute de forma física e psicológica. De acordo com esses autores, a dor, em geral, é motivo de atendimento médico em 52,2\% a 61,2\% nos serviços de emergência, o que torna sua avaliação e prevenção elementos fundamentais. 
De caráter pessoal e subjetivo, a dor sofre influência de fatores culturais, situacionais e outras variáveis. Numa revisão de medida de dor, Silva e Ribeiro-Filho (2011) descrevem algumas técnicas psicofísicas que permitem mensurar diferentes dimensões sensoriais e afetivas da percepção da dor, destacando a validade e fidedignidade dessas técnicas, além do uso em ambiente clínico. Entre essas técnicas cita-se a que trata da função da potência da dor a partir dos estímulos, provocando diferentes sistemas sensoriais; outra técnica seria aquela voltada para a amplitude dos estímulos.

A avaliação da dor em crianças, segundo revisão de literatura feita por Cohen et al. (2008), pode ser feita por meio de um grande número de medidas, segundo as necessidades particulares que os profissionais encontram. Numa avaliação de evidências de base sobre instrumentos de avaliação da dor pediátrica, os autores examinaram 17 medidas compostas por autorrelatos, questionários, diários e escalas de observação do comportamento. Para o futuro da avaliação da dor, os autores destacam a importância da identificação dos significados ou das variações culturais e seu impacto no funcionamento do indivíduo (Cohen et al., 2008). Em outro estudo de revisão focando a avaliação do comportamento da criança na fase pré-escolar em situação de dor, Correia e Linhares (2008) apontam para a verificação das propriedades psicométricas de instrumentos de avaliação de dor, sendo o indicador de atividade facial e a dimensão da intensidade as medidas mais utilizadas. Ao mesmo tempo, as autoras destacam a carência de estudos, no Brasil, sobre tradução e adaptação de instrumentos para avaliação da dor pediátrica.

Ainda nessa linha de estudo sobre medidas de avaliação, Rossato e Magaldi (2006) verificaram, pelos Cartões das Qualidades da dor, diferenças entre a percepção da qualidade sensorial da dor em crianças e adolescentes hospitalizados, demonstrando a sensibilidade do instrumento para avaliar, discriminar e mensurar diferentes dimensões da dor em diferentes idades. Além disso, destacaram a necessidade dos profissionais de saúde em entender as características do desenvolvimento e comportamento da criança para ser capaz de avaliar a dor.

Outras variáveis também são importantes no estudo da dor, tanto que a relação entre temperamento, comportamento e experiência dolorosa na trajetória do desenvolvimento infantil foi abordada num estudo de revisão de literatura sobre essa relação por Klein e Linhares (2007), em especial sobre o desenvolvimento das crianças nascidas prematuras. De modo geral, as autoras constataram que o temperamento foi um fator preditor para padrões individuais de reação à dor e a problemas de comportamento das crianças em diferentes idades.

Além das variáveis indicadas, a lembrança da dor também influencia e afeta emocionalmente as crianças, como mostra o estudo de Noel, McMurtry, Chambers e McGrath (2010) que investigaram a memória de crianças com idade entre 5 e 10 anos, em relação à intensidade e ansieda- 
de vividas em situação de experiência em procedimentos dolorosos. Os pesquisadores verificaram que a experiência direta da intensidade da dor e os comportamentos da equipe médica durante a punção venosa são lembrados de modo associado pelas crianças. Esses dados destacam a importância do efetivo manejo da dor durante procedimentos médicos.

No que se referem aos aspectos da intervenção na experiência da dor, técnicas não farmacológicas (distração, relaxamento muscular progressivo, massagem, respiração, biofeedback) para controle da dor da AF administradas pelas crianças ou cuidadores em suas próprias casas, também têm sido eficazes (Bonner, Hady, Ezell, \& Ware, 2010; Dampier, 2008; Lemark \& Ranalli, 2009), apesar de tradicionalmente o tratamento se concentrar em seus aspectos físicos (Thomas, Gruen, \& Shu, 2001). Mussa e Malerbi (2008) constataram os efeitos positivos de uma intervenção por meio de atividades lúdicas desenvolvidas por um grupo de contadores de histórias no estado emocional e nas queixas de dor de crianças hospitalizadas com neoplasias malignas.

Mais recentemente, em estudo que buscou verificar diferenças de idade e desenvolvimento na atenção seletiva de crianças frente à distração interativa e passiva na dor aguda, Wohlheiter e Dahlquist (2012) observaram, de acordo com o modelo neurocognitivo de dor, que as crianças foram as que mais se beneficiaram com a distração interativa. Já as crianças mais velhas demonstraram maior tolerância para a dor.

Além da avaliação e intervenção sobre a dor em crianças, outro aspecto a ser observado refere-se às suas estratégias de enfrentamento (EE) ou coping diante dos episódios dolorosos. Segundo Van Damme, Crombez e Eccleston (2008), o coping "é normalmente usado para significar qualquer comportamento que pode ser observado em resposta a uma ameaça, independentemente do seu sucesso" (p. 1). No que se refere ao coping da dor, os autores consideram que o mais importante é entender a forma como as pessoas lutam para dar sentido à experiência indesejada e como evitam, adaptam ou alteram as causas percebidas nessa experiência. Nesse sentido, numa perspectiva motivacional para entender o coping da dor, Van Damme et al. (2008) salientam a importância de entender a ideia de lidar com a dor crônica reformulando-a dentro de uma literatura que englobe objetivos de vida e autorregulação.

Dentro desta perspectiva de autorregulação, o coping tem sido definido como "esforços intencionais conscientes para regular a emoção, cognição, comportamento, fisiologia e ambiente em resposta a eventos estressantes ou circunstâncias" (Compas et al., 2001, p. 89), de forma que o nível de desenvolvimento do indivíduo, tanto contribui para os recursos que estão disponíveis para o enfrentamento quanto limita suas formas de lidar.

Para estes autores, a compreensão dos efeitos da idade e diferenças individuais no enfrentamento (como sexo, nível cognitivo e status socioeco- 
nômico, por exemplo), são variáveis importantes para o estudo do coping, contribuindo para definir o curso do desenvolvimento de enfrentamento.

Neste aspecto, pesquisadores do desenvolvimento têm cada vez mais convergido em conceituações de enfrentamento como «regulação sob estresse» (Skinner \& Zimmer-Gembeck, 2007, p. 122), para o estudo de mudanças no processo de enfrentamento em diferentes idades. Consideram que a maneira como crianças e adolescentes lidam com o estresse pode influenciar o seu impacto imediato e futuro e o modo como se ajustam; favorecer trajetórias de desenvolvimento mais adaptativas e ser um precursor de padrões de enfrentamento durante a vida adulta (Compas et al., 2001).

Este modelo de enfrentamento tem a teoria de base reconhecida como Teoria Motivacional do Coping (MTC, de Motivational Theory of Coping) desenvolvida por Skinner e Werborn (1994) e ampliada por Skinner e colaboradores, $(2003,2007)$ sendo coping definido como "o modo como as pessoas regulam o seu comportamento, as suas emoções e a sua orientação motivacional sobre condições de estresse psicológico" (Skinner \& Wellborn, 1994, p. 107).

Buscando identificar e analisar como o coping tem sido conceituado, classificado e categorizado, Skinner et al. (2003) realizaram uma revisão de literatura e identificaram cerca de 100 estudos sobre esse constructo ao longo de vinte anos. Após a análise dos estudos, identificaram e descreveram um pequeno número de categorias de ordem superior ou famílias de enfrentamento principais, "talvez uma dúzia ou assim, que pode ser usado para classificar a maioria, se não todas as formas de lidar identificadas em pesquisas anteriores" (p. 125). Assim, foram identificadas 12 famílias de enfrentamento: Autoconfiança, Busca de suporte, Resolução de Problemas, Busca de Informações, Acomodação, Negociação, Delegação, Isolamento, Desamparo, Fuga, Submissão e Oposição. Essas categorias foram tomadas como referência neste estudo.

Diante do exposto, considerando a gravidade da sintomatologia da $A F$, e seu impacto sobre o crescimento e desenvolvimento infantil, podendo comprometer aspectos cognitivos e sociais, e a qualidade de vida das crianças, este estudo buscou identificar, descrever e analisar as características da dor da AF (último episódio de dor lembrado), o impacto da dor nas atividades de vida diária, as técnicas de manejo e as estratégias de enfrentamento adotadas pelas crianças para lidar e controlar a dor.

Da mesma forma, considerando que os cuidadores ${ }^{3}$ são os principais responsáveis pelos manejos domiciliares dos sintomas da doença, buscamos também analisar e comparar as respostas das crianças e seus cuidadores, com o objetivo de identificar concordâncias e discrepâncias entre elas.

3 Termo utilizado significando Cuidador em atendimento de saúde: "qualquer indivíduo envolvido no processo de identificar, prevenir ou tratar uma doença ou incapacidade" (American Psychological Association [APA], 2010, p. 246). 


\section{Método}

\section{Delineamento}

Este estudo utilizou o método de estudo descritivo-comparativo (Meltzoff, 2001), o qual procurou descrever e comparar a percepção do episódio doloroso da AF entre crianças e seus cuidadores ${ }^{4}$.

\section{Participantes}

Participaram do estudo, 27 pares de cuidador-criança com diagnóstico de Anemia Falciforme (CID.10:D57.0), que frequentavam centros de referência para tratamento da Doença Falciforme em dois Estados brasileiros, Espírito Santo e Mato Grosso. As amostras foram pareadas quanto às variáveis: (a) ter diagnóstico de AF, espectro Hb-SS, pelo fato de ser o espectro de maior gravidade (Agência Nacional de Vigilância Sanitária [ANVISA], 2002); (b) ter tido pelo menos um episódio de dor nos últimos 6 meses, para garantir o relato retrospectivo da dor; e (c) ter idade entre 7 e 12 anos, devido à possibilidade de já possuir repertório verbal suficiente para emitir informações acerca da situação da doença e compreensão das atividades propostas.

A amostra do Espírito Santo foi constituída por 11 crianças, sendo 7 meninos, com média de idade de 9 anos e 3 meses, que frequentavam o Ambulatório de Pediatria do Hospital Universitário "Cassiano Antônio de Moraes" (HUCAM) da Universidade Federal do Espírito Santo em Vitória/ ES e seus cuidadores (11 mães), com média de idade de 31 anos.

Outra parte da amostra foi composta por 16 crianças (8 meninos), com idade média de 10 anos e 4 meses, e seus cuidadores (15 mães e 1 pai), com média de idade de 38 anos e 11 meses. As crianças recebiam atendimento em uma Unidade de Saúde Pública Hemocentro da cidade de Cuiabá/MT.

Nos dois Estados, a identificação da AF passou a ocorrer na rede pública por meio do exame do pezinho pelo Programa Nacional de Triagem Neonatal (PNTN) a partir do ano de 2001 e os dois centros de referência de atendimento seguiam o protocolo clínico e as diretrizes terapêuticas para tratamento da Doença Falciforme em consonância com a Política Nacional de Atenção às Pessoas com DF e outras Hemoglobinopatias (Portaria n 1.391/GM de 16 de agosto de 2005; Brasil, 2008).

\section{Instrumento}

Para investigar a percepção das crianças e seus cuidadores frente à dor da AF, foi aplicado o Protocolo de avaliação da percepção, impacto e manejo da dor da AF - [PAPIM-AF] - versão criança (PAPIM-AF-CRI) e versão cuidadores (PAPIM-AF-CUI) - adaptado do protocolo de Alvim (2010),

Este estudo foi desenvolvido a partir de um projeto integrado entre duas instituições de ensino do país. 
contendo dados sobre:I - Percepção e caracterização da dor: frequência, duração e descrição da ultima crise dolorosa; intensidade das crises dolorosas (Faces Pain Scale-Revised - FPS-R) - (traduzida do estudo de Hicks, von Baeyer, Spafford, van Korlaar, \& Goodenough, 2001, para a população brasileira por Poveda et al., 2010); localização dos pontos dolorosos (registrados num diagrama corporal); reconhecimento ou não do episódio doloroso como característico da doença; atividades que as crianças faziam antes do episódio; como a criança se sente, de uma maneira geral e em relação à dor; II - Impacto da dor nas atividades de vida diária: impossibilidade de realização de alguma atividade da vida diária e por quanto tempo; III - técnicas de manejo da dor: qual estratégia farmacológica e não farmacológica utilizada para alívio da dor; e IV- estratégias de enfrentamento utilizadas no momento de dor.

\section{Aspectos éticos}

A coleta de dados ocorreu ao longo do ano de 2011, após aprovação pelos Comitês de Ética da UFES (Proc. n. 99/10) e da UFMT (Proc. n. 889/10). A aplicação do instrumento foi realizada individualmente e separadamente, sendo primeiro aplicado no cuidador, após assinatura do termo de consentimento.

\section{Análise dos dados}

Para a análise dos dados relacionados à caracterização da dor como localização, intensidade, tipo, duração, entre outros, considerou-se as respostas das crianças e dos cuidadores em termos de frequência das duas amostras. Uma vez reunidos os dados das amostras, estes foram analisados de forma descritiva e inferencial (Teste t de Student) em relação à proporção média das respostas dadas pelas crianças e seus cuidadores quanto à intensidade, duração e localização. Quanto ao aspecto da relação com a dor no cotidiano, as técnicas de manejo e a interferência da dor nas atividades de vida diária, estes foram analisados com base na frequência de respostas contidas no instrumento. As respostas de crianças e cuidadores para as estratégias de enfrentamento foram identificadas com base nas categorias de ordem superior descritas por Skinner et al. (2003) e destacadas anteriormente.

\section{Resultados}

A crise de dor é um dos sintomas clínicos mais recorrentes na AF, constituindo-se em uma das causas mais frequentes de atendimento 
em emergência (Sena \& Tostes, 2011); dessa forma, este estudo avaliou e comparou a dor da AF na percepção das crianças (CRI) e de seus cuidadores (CUI) em relação à caracterização da dor (último episódio de dor lembrado), ao impacto da dor nas atividades de vida diária, às técnicas de manejo e as estratégias de enfrentamento da situação dolorosa.

No que se refere à caracterização da dor pelo cuidador e pela criança com AF, estes demonstram percepções diferenciadas e semelhantes (Tabela 1). Observa-se concordância entre os relatos das crianças (CRI) e dos cuidadores (CUI), em relação à percepção da dor e sua relação com a $\mathrm{AF}(\mathrm{CRI}=85,2 \% ; \mathrm{CUI}=82,5 \%)$. Também houve concordância quanto à localização da dor: a maioria $(\mathrm{CRI}=73,0 \% \mathrm{CUI}=75,0 \%)$ se referiu à região do tronco compreendida pelas regiões abdômen e peito como principais locais da sensação dolorosa, seguidos da dor nos membros (CRI = 23,0\%; CUI $=20,8 \%$ ) (Tabela 1).

Tabela 1

Caracterização da dor por criança e cuidador $(\mathrm{n}=27)$

\begin{tabular}{|c|c|c|c|c|c|}
\hline \multirow[t]{2}{*}{ Categorias } & \multicolumn{2}{|c|}{ Criança } & \multicolumn{2}{|c|}{ Cuidador } & \multirow[t]{2}{*}{${ }^{*} p$ valor } \\
\hline & $\mathrm{N}$ & $\%$ & $\mathrm{~N}$ & $\%$ & \\
\hline \multicolumn{6}{|l|}{ Relação com AF } \\
\hline $\mathrm{Sim}$ & 18 & 85,2 & 21 & 82,5 & 1 \\
\hline Não & 3 & 14,2 & 3 & 12,5 & \\
\hline \multicolumn{6}{|l|}{ Intensidade } \\
\hline Mínima & 4 & 14,8 & 3 & 11,1 & \\
\hline Moderada & 7 & 25,9 & 14 & 51,8 & 0,379 \\
\hline Forte & 16 & 59,2 & 10 & 37,0 & \\
\hline \multicolumn{6}{|l|}{ Localização } \\
\hline Cabeça & 1 & 3,5 & 1 & 4,1 & \\
\hline Tronco & 19 & 73,0 & 18 & 75,0 & 1 \\
\hline Membros & 6 & 23,0 & 5 & 20,8 & \\
\hline \multicolumn{6}{|l|}{ Tipo } \\
\hline Queimação & 7 & 25,9 & 3 & 11,1 & \\
\hline Aperto & 11 & 40,7 & 3 & 11,1 & $0,005^{*}$ \\
\hline Outros & 9 & 33,3 & 21 & 77,7 & \\
\hline \multicolumn{6}{|l|}{ Duração } \\
\hline Até 1 dia & 14 & 63,6 & 12 & 54,5 & 1 \\
\hline Mais de 1 dia & 8 & 36,3 & 10 & 45,4 & \\
\hline \multicolumn{6}{|l|}{ Fatores desencadeantes } \\
\hline Atividade & 14 & 70 & 14 & 66,6 & 1 \\
\hline Descansando ou dormindo & 6 & 30 & 7 & 33,3 & \\
\hline
\end{tabular}




\begin{tabular}{lccccc}
\hline $\begin{array}{l}\text { Avaliação da última crise } \\
\text { Mais forte }\end{array}$ & 10 & 47,6 & 2 & 10 & $0,003^{*}$ \\
Menos forte & 11 & 52,3 & 18 & 90 & \\
\hline $\begin{array}{l}\text { Presença de dor recente } \\
\text { Sim }\end{array}$ & 10 & 37,0 & 9 & 33,3 & 0,712 \\
Não & 17 & 62,9 & 18 & 66,6 & \\
\hline $\begin{array}{l}\text { Estado da criança na ultima } \\
\text { semana }\end{array}$ & 17 & 62,9 & 21 & 77,7 & 0,211 \\
$\begin{array}{l}\text { Bem } \\
\text { Mais ou menos }\end{array}$ & 10 & 37,0 & 6 & 22,2 & \\
\hline
\end{tabular}

Nota. Legenda: *Teste $t(\mathrm{p} \geq 0,05)$

Quando questionados sobre a percepção da intensidade da última dor sentida, observa-se que para a maioria das crianças a dor é considerada do tipo forte $(59,2 \%)$, enquanto que os cuidadores tendem a considerá-la com maior frequência do tipo moderada $(51,8 \%)$.

$\mathrm{Na}$ avaliação do tipo de dor, as respostas das crianças e de seus cuidadores se diferenciaram significativamente $(p=0,05)$ : para as crianças $(40,7 \%)$ a dor ocorria em forma de "aperto"; enquanto os cuidadores $(77,7 \%)$ se referiam às dores classificadas como de outro tipo como "em fincada", "profunda" e "moendo". Já em relação à duração da dor, para ambos os grupos, a dor é na maioria das vezes de um dia. Embora a maioria das respostas faça referência a um dia de duração, em relação aos cuidadores, verificou-se que estes também consideraram que da dor durava mais de um dia (Tabela 1).

Quando questionadas se o último episódio de dor lembrado foi mais forte ou não do que o anterior, houve concordância entre as respostas em que a maioria das crianças (52,3\%) e dos cuidadores (90,0\%) disse não. Porém esta diferença de percentual foi significativamente diferente $(p=0,05)$.

Quanto aos possíveis fatores que desencadeiam as dores na $\mathrm{AF}$, a maior parte da amostra $(\mathrm{CRI}=70,0 \% ; \mathrm{CUI}=66,6 \%)$ concordou que, antes da dor, as crianças estavam realizando atividades de lazer, como jogar bola, tomar sol na praia ou brincar, ou atividades escolares (Tabela 1).

Quanto à presença de crise de dor recente, isto é, na última semana vivida pelas crianças, tanto crianças quanto cuidadores em maior frequência não evidenciaram presença de crise de dor. Além disso, o estado geral da criança na última semana foi percebido pelas crianças e cuidadores como condição geral de saúde de bem estar, principalmente, pelos cuidadores (Tabela 1).

Quando avaliadas sobre o impacto da dor nas atividades de vida diária das crianças, houve concordância entre as respostas, indicando seu impacto sobretudo nas atividades cotidianas (dormir, sentar, deitar e comer) e de lazer (brincar, ver televisão e passear). Ao mesmo tempo, observou-se um impacto negativo também na vida dos cuidadores, em 
relação às atividades do cotidiano (dormir e se alimentar) e laborais (sair para trabalhar) (Tabela 2).

Em relação às técnicas de manejo da dor, as crianças e seus cuidadores demonstraram fazer uso de medicamentos, seguido de procurar assistência hospitalar para aliviar a situação dolorosa (Tabela 2).

Em relação às famílias de enfrentamento da dor, investigou-se o pensamento da criança e do cuidador em relação às crises de dor. No momento da dor as crianças e os cuidadores apresentaram com maior frequência a família de coping Submissão ( $\mathrm{CRl}=70,4 \%$; $\mathrm{CUI}=77,8 \%$ ) demonstrando focar nos aspectos negativos da situação estressante. Desamparo foi a segunda família de coping mais citada por ambos os grupos $(\mathrm{CRI}=$ $22,2 \%$; $\mathrm{CUI}=14,8 \%$ ), que envolve a presença de comportamentos que demonstram passividade, desânimo e pessimismo.

Tabela 2

Relação com a dor no cotidiano e estratégias de manejo da dor para cuidador e crianças com $A F(n=27)$

\begin{tabular}{lcccc}
\hline \multirow{2}{*}{ Categorias } & \multicolumn{2}{c}{ Criança } & \multicolumn{2}{c}{ Cuidador } \\
\cline { 2 - 6 } & $\mathrm{N}$ & $\%$ & $\mathrm{~N}$ & $\%$ \\
\hline Interferência na vida da criança & & & & \\
Necessidades do cotidiano (sono, alimento) & 27 & 39,7 & 27 & 35,5 \\
Estudar e atividades da escola & 19 & 27,9 & 22 & 28,9 \\
Lazer & 22 & 32,3 & 27 & 35,5 \\
\hline Interferência na vida do cuidador & & & & \\
Necessidades do cotidiano & - & - & 21 & 58,3 \\
Trabalhar & - & - & 13 & 36,1 \\
Estudar & - & - & 2 & 5,5 \\
\hline Estratégias de manejo da dor & & & & \\
Medicamentos & 25 & 51 & 27 & 52,9 \\
Hospitalização & 15 & 30,6 & 19 & 37,2 \\
Massagem & 8 & 13,6 & 5 & 9,8 \\
Chá & 1 & 2,0 & - & - \\
\hline
\end{tabular}




\section{Discussão}

Estudos que avaliam a percepção da dor da AF por múltiplos informantes (crianças e ou cuidadores e ou agentes de saúde) têm encontrado resultados inconclusivos. Dados na literatura apontam discrepâncias entre a percepção da criança e do cuidador em relação à intensidade da dor e suas consequências (Gil et al., 2000; Graumlich et al., 2001; Tostes et al., 2009). As justificativas para essas diferenças podem estar relacionadas ao caráter subjetivo e multifatorial da dor (Lobo et al., 2007), a aspectos da própria criança (desenvolvimento atípico, cognição e motivação) e a fatores do contexto familiar e cultural (Correia \& Linhares, 2008).

Em nossa amostra, observou-se discrepância em relação à intensidade da última dor percebida pelas crianças e pelos cuidadores, os quais subestimaram a dor dos filhos. Os resultados foram coerentes com os obtidos por Graumlich et al. (2001), ao avaliarem a intensidade da dor da AF em 25 crianças, com idade entre 7 a 12 anos, e a percepção por parte dos pais. Correia e Linhares (2008), em uma revisão de literatura, também encontraram resultados semelhantes ao observarem nos pais uma tendência a subestimar a dor do filho, sobretudo em crianças em idade pré-escolar e que apresentam algum atraso cognitivo ou necessidades especiais. Entretanto, esse padrão não é unânime, conforme estudo feito por Tostes et al. (2008), que verificaram que os pais tenderam a superestimar significativamente a dor do filho.

Observou-se, ainda, discrepância em relação ao tipo de dor, sendo os cuidadores mais discriminativos do que a maioria das crianças. Elas se referiram à dor como um "aperto", enquanto seus cuidadores tinham a sensação de que a dor dos seus filhos era, sobretudo, do tipo "em fincada", "profunda" e "moendo". Esses resultados permitem considerar que, devido ao caráter subjetivo e multidimensional da dor, sua aferição pode ser difícil por qualquer outra pessoa que não aquela que a sente. Dificuldade que ocorre, sobretudo na infância, diante das características desenvolvimentais da criança, conforme afirmam Murta (1999) e Guimarães (1999).

Quanto à localização da dor, houve concordância na percepção entre os grupos. Mais da metade dos participantes se referiu ao tronco (abdômen e peito) como principais sítios da sensação dolorosa, seguidos dos membros, conforme estudo feito por Tostes et al. (2008). Os autores estudaram a crise dolorosa da AF por meio de diários e diagrama do corpo para localizar a dor e observaram que, em $75 \%$ dos pacientes, a dor ocorreu no abdômen, seguida das extremidades e do tórax.

De acordo com estudos sobre os aspectos clínicos da dor na AF, ela pode ser desencadeada espontaneamente ou em decorrência de frio, traumas, esforço físico, desidratação, estresse, fadiga, esforço excessivo, infecções e hipóxia (Brasil, 2009; Lobo et al., 2007; Walco \& Dampier, 1990). 
Conforme relatos das crianças e de seus cuidadores, observa-se que a maioria, de ambos os grupos, relatou que atividades físicas de lazer, como correr, jogar bola, agitar e pular, contribuem para a manifestação e piora do episódio doloroso. Esses resultados sugerem que tanto os pais quanto as crianças demonstraram habilidade para distinguir fatores capazes de desencadear ou potencializar a dor, servindo como mecanismo de proteção para as crianças. Por outro lado, algumas crianças relataram que a dor começou quando estavam dormindo, o que remete ao caráter imprevisível da dor na AF (Armstead \& D'Souza, 2011).

Ao avaliar as consequências da dor na vida infantil, observou-se que, na percepção de ambos os grupos, ela exerceu importante impacto em diversas esferas da vida cotidiana, de lazer e escolares das crianças. Tais constatações são coerentes com os resultados obtidos por Lemanek e Ranalli (2009), Silva e Marques (2007) e Tostes et al. (2008). Além disso, de acordo com a literatura, essas limitações, aliadas à grande variedade, gravidade dos sintomas e dificuldade de controle do episódio doloroso, podem contribuir para o desenvolvimento de problemas internalizantes (ansiedade e depressão) e de ajustamento social, comuns nessa população (Anie, 2005; Bonner et al., 2008; Santos \& Miyasaki, 1999, Thompson et al., 1993).

O impacto da dor da criança também foi observado na vida dos cuidadores. A maioria deles $(58,3 \%)$ apresentou dificuldades na realização de atividades do cotidiano, como dormir e se alimentar e laborais (sair para trabalhar). Esses resultados são condizentes com os da literatura, que apontam que a doença na infância pode gerar consequências negativas na vida das famílias, sobretudo somáticas, estresse parental, isolamento social e problemas de ajustamento (Castro \& Piccinini, 2002; Colleto \& Câmara, 2009; Guimarães, Miranda, \& Tavares, 2009; Lemanek \& Ranalli, 2009; Silva \& Marques, 2007).

Quando questionadas sobre o modo como enfrentam a situação dolorosa, observou-se que as respostas das crianças e dos cuidadores foram semelhantes, demonstrando foco nos aspectos negativos da experiência dolorosa (Submissão), e sentimentos de pessimismo e desânimo (Desamparo). Esses sentimentos são comuns em crianças com doenças crônicas (Lima, 2009; Moraes \& Enumo, 2008; Motta \& Enumo, 2010) e em crianças com AF, caracterizados por "pensamento negativo" (catastrofização, isolamento, medo e raiva) (Anie et al., 2002; Gil, Williams, Thompson Jr., \& Kinney, 1991; 1993).

O uso predominante destes modos de enfrentamento pode colocar crianças e cuidadores em risco para um desfecho adaptativo negativo diante da dor da AF e potencializar a sensação de falta de controle do estressor, gerando ansiedade e depressão. Estes resultados reforçam a observação de Van Damme et al. (2008) a respeito da necessidade de entender a dor crônica a partir da autorregulação e dos aspectos motivacionais do indivíduo. 
Em relação ao manejo da dor da AF, muitos dos episódios dolorosos podem ser controlados em domicílio, utilizando-se analgésicos via oral ou outras condutas não farmacológicas, dependendo da intensidade da dor da criança (Tostes et al., 2009). Além disso, os cuidadores são orientados a procurar assistência médica sempre que a dor não melhorar, ou caso surjam sintomas como febre ou queda do estado geral (Lobo et al., 2007). Diante disso, observou-se em ambos os grupos a tendência ao uso domiciliar de medicamentos para alívio da dor, seguido de hospitalização, conforme a orientação médica e também do Ministério da Saúde (Brasil, 2009).

Entretanto, destaca-se que, apesar da adequação dos procedimentos de manejo utilizados pelos pares, observa-se que toda a situação que envolve a experiência da dor da criança parece não ser percebida sem sofrimento. Essa condição demonstra que, apesar de os cuidadores e as crianças seguirem as orientações para controle da dor, o uso exclusivo de uma técnica de manejo pode dificultar a adaptação bem sucedida à dor e aumentar a frustração e as limitações devido a tal condição (Lauwerier et al., 2012). O que indica a necessidade de intervenção psicológica para orientações sobre o uso de técnicas não farmacológicas.

Além disso, de acordo com Anie (2005), o uso excessivo ou exclusivo de medicamentos para controle da dor da $A F$, apesar de infundadamente associado à dependência psicológica por parte dos pacientes, parece estar mais associado a outros fatores, como: estado de humor, impacto nas atividades de vida diária, problemas de comportamento relacionados à dor e ao uso inadequado de estratégias de enfrentamento (Anie et al., 2002; Elander et al., 2004). É uma situação que aponta, novamente, para a necessidade de orientações sobre uso de outras técnicas de controle da dor.

\section{Considerações finais}

A despeito do cuidado com a saúde infanto-juvenil, em 1995 o Conselho Nacional de Direitos da Criança e do Adolescente, por meio da Resolução № 41, estabelece direitos prioritários da criança e do adolescente, dentre eles, o "7. Direito a não sentir dor, quando existam meios para evitá-la." e o "8. Direito a ter conhecimento adequado de sua enfermidade, dos cuidados terapêuticos e diagnósticos a serem utilizados, do prognóstico, respeitando sua fase cognitiva, além de receber amparo psicológico, quando se fizer necessário" (Brasil, 1995).

De acordo com os resultados do presente estudo, fica evidente o quanto o desafio de estudar a dor em crianças é complexo, sobretudo diante de sua natureza subjetiva e das inúmeras variáveis que podem servir como mediadoras da experiência dolorosa. Entretanto, avaliar a dor em termos de suas características, impacto, estratégias de enfrentamento e 
de manejo é uma medida de proteção, por subsidiar medidas que possam minorar o potencial efeito nocivo da dor no desenvolvimento infantil.

Dessa forma, os resultados deste trabalho evidenciaram a necessidade no país de estudos empíricos sobre a dor da AF e seu impacto no desenvolvimento infantil, mostrando divergências e convergência na percepção da dor da AF por múltiplos informantes. Além disso, demonstraram a importância do estudo do coping da dor em crianças com doença falciforme e em seus cuidadores. Assim, será possível desenvolver propostas de intervenção que visem um repertório de estratégias de enfrentamento adaptativas de modo a proporcionar uma melhor qualidade de vida a esta população.

\title{
Pain the daily life of caregivers and children with sickle cell anemia
}

\begin{abstract}
The crises of chronic or acute pain, of varying intensity and unpredictable recurrence are one of the most common symptoms in sickle cell disease and tend to affect the quality of life of people with this disease. This study examined the impact of pain on daily life and the coping strategies of caregivers and children with sickle cell anemia. The participants were 27 pairs of caregiver-child, being formed by 11 pairs of children treated at the Pediatric Clinic of the Hospital Universitario Cassiano Antonio de Moraes Vitória / ES and sixteen pairs composed of children who attended the Blood Center of Cuiabá / MT. The results revealed differences in perception of the caregiver and child characterization of pain regarding type and intensity. The pain crises interfere, mainly in daily activities. The most frequently used coping strategy focused on thoughts that involve the negative aspects of the unwanted experience.
\end{abstract}

Keywords: Sickle cell anemia. Pain. Caregiver. Child.

\section{Dolor en los cuidadores diarios y los niños con anemia de células falciformes}

Resúmen: Las crisis de dolor agudo o crónico de diferente intensidad y recurrencia impredecible son uno de los síntomas más comunes de la enfermedad de células falciformes y tienden a afectar a la calidad de vida de quienes la padecen. Este estudio trata de describir y comparar la percepción del doloroso episodio de anemia falciforme entre los niños y sus cuidadores. Entre los participantes había 27 pares de cuidadorniño, estando formados por 11 hijos parejas tratadas en la Clínica Pediátrica del Hospital Universitario Cassiano Antonio de Moraes Vitória/ES y 16 pares integrados por niños que asisten al Hemocentro de Cuiabá/MT. Los resultados revelaron diferencias en la percepción del niño y cuidador de la caracterización del dolor en cuanto al tipo e intensidad. Las crisis de dolor interfieren especialmente en las actividades cotidianas. La estrategia de afrontamiento más utilizada por ambos grupos se centró en pensamientos 
que incumban a los aspectos negativos de la experiencia no deseada, lo que indica la necesidad de intervención psicológica con esta población.

Palabras clave: Anemia de células falciformes. Dolor. Cuidador. Niño.

\section{La douleur dans la vie quotidienne des aidants et des enfants atteints d'anémie falciforme}

Resumé: Les épisodes de douleur aiguë ou chronique, d'une intensité différente et récurrence imprévisible sont un des symptômes plus fréquents dans la maladie d'anémie falciforme et ont tendance à affecter la qualité de vie des personnes atteintes de la maladie. Cet étude a examiné l'impact de la douleur quotidienne et stratégies d'adaptation des soignants et des enfants atteints d'anémie falciforme. Ont participé de cet étude 27 paires de soignant-enfant, parmi eux, 11 couples ont étés formés par des enfants assistés à la clinique pédiatrique de l'Hôpital Universitaire Cassiano Antônio de Moraes de Vitória/ES, et 16 paires ont étés composés d'enfants qui ont fréquenté le Hemocentro de Cuiabá/MT. Les résultats ont révélé les différences dans la perception du soignant et des l'enfant sur la caractérisation de la douleur en ce qui concerne le type et l'intensité. Les épisodes de douleur interfèrent, en particulier, dans l'activités de la vie quotidienne. L'stratégie d'adaptation la plus utilisée a été axé sur les pensées qui comportent des aspects négatifs de l'expérience non souhaité.

Mots-clés: Anémie falciforme. Douleur. Soignant. Enfant.

\section{Referências}

Agência Nacional de Vigilância Sanitária. (2002). Manual de diagnostico e tratamento de doenças falciforme. Brasília, DF. Recuperado de http://bvsms.saude.gov.br/bvs/ publicacoes/anvisa/diagnostico.pdf

Alvim, R. C. (2010). Perfil e impacto da dor em crianças e adolescentes com doença falciforme. Recuperado de: http://www.cehmob.org.br/downloads/artigocarrusca

American Psychological Association. (2010). Dicionário de psicologia (D. Bueno, M. A. V. Veronese \& M. C. Monteiro, trads.). Porto Alegre, RS: ArtMed.

Anie, K. A., Steptoe, A., Ball, S., Dick, M., \& Smalling, B. M. (2002). Coping and health service utilisation in a UK study of paediatric sickle cell pain. Archives of Disease in 
Childhood, 86, 325-329.

Anie, A. K. (2005). Psychological complications in sickle cell disease. British Journal of Haematology, 129, 723-729.

Armstead, V. E., \& D'Souza, G. (2011). Sickle cell pain. In B. C. McClain \& S. Santhanam, Handbook of pediatric chronic pain. New York, NY: Springer.

Bandeira, F. M. G. C., Peres, J. C., \& Carvalho, E. J. (2004). Hidroxiuréia em pacientes com síndromes falciformes acompanhados no Hospital Hemope, Recife-PE. Revista Brasileira Hematologia e Hemoterapia, 26(3), 189-194.

Bonner, M. J., Hady, K. K., Ezell, E., \& Ware, R. (2010). Hematological disorders: sickle cell disease and hemophilia. In R. T. Brown, Handbook of pediatric sychology in school settings (pp. 241-261). USA: Routledger.

Brasil, Conselho Nacional dos Direitos da Criança e do Adolescente. (1995, 17 de outubro). Resolução № 41 de 09 de outubro de 1995 - Direitos da criança e do adolescente. Diário Oficial da União (Seção 1).

Brasil, Ministério da Saúde. (2008). Manual de educação em saúde: autocuidado na doença falciforme. Brasília, DF: Recuperado de http://bvsms.saude.gov.br/bvs/ publicacoes/manual_educacao_saude_volume1.pdf

Brasil, Ministério da Saúde, Departamento de Atenção Especializada. (2009). Manual de eventos agudos em doença falciforme. Brasília, DF. Recuperado de http:// bvsms.saude.gov.br/bvs/publicacoes/manual_eventos_agudos_doenca_ falciforme.pdf

Brasil, Ministério da Saúde. (2012). Doença falciforme condutas básicas para tratamento. Brasília, DF: Recuperado de bvsms.saude.gov.br/bvs/publicacoes/ doenca_falciforme_condutas_basicas.pdf

Cançado, R. D., Lobo, C., Ângulo, I .L., Araújo, P. I. C., \& Jesus, J A. (2009). Protocolo clínico e diretrizes terapêuticas para uso de hidroxiureia na doença falciforme. Revista Brasileira de Hematologia e Hemoterapia, 31(5), 361-366.

Castro, E. K., \& Piccinini, C. A. (2002). Implicações da doença orgânica crônica na infância para as relações familiares: algumas questões teóricas. Psicologia: Reflexão e Crítica, 15(3), 625-635.

Cohen, K., Lemanek, K., Blount, R. L., Dahlquist, L. M., Lim, C. S., Parlermo, T. M., McKenna, K. D., \& Weiss, K. E. (2008). Evidence-base assessment of pediatric pain. Journal of Pediatric Psychology, 3(9), 939-955. 
Coletto, M., \& Câmara, S. (2009). Estratégias de coping e percepção da doença em pais de crianças com doença crônica: o contexto do cuidador. Revista Diversitas Perspectivas em Psicologia, 5, 97-110.

Compas, B. E., Connor-Smith, J. K., Saltzman, H., Thomsen, A. H., \& Wadsworth, M. E. (2001). Coping with stress during childhood and adolescence: Problems, progress, and potential in theory and research. Psychological Bulletin, 127, 87-127.

Correia, L. L., \& Linhares, M. B. M. (2008). Assessment of the behavior of children in painful situations: Literature review. Jornal de Pediatria, 84(6), 477-486.

Costa, P. C. M., Lyra, I. M., \& Sena, T. S. (2011). Síndrome torácica aguda. Revista Baiana de Pediatria, 5(1), 57-59.

Craychete, D. C., \& Wanderley, S. B. C. (2011). Dor na criança: avaliação e terapêutica (Fascículo 2). Recuperado de Sociedade Brasileira para o Estudo da Dor www. sbed.org.br

Dampier, C. (2008). Pain in sickle cell disease. In G. A. Walco \& K. R. Goldscheneider, Pain in children: A pratical guide for primary care (pp. 201-207). USA: Humana Press.

Diniz, D., \& Guedes, C. (2003). Anemia faliforme: um problema nosso. Uma abordagem bioética sobre a nova genética. Cadernos de Saúde Pública, 19(6), 1761-1770.

Elander J., Lusher, J., Bevan, D., Telfer, P., \& Burton, B. (2004). Understanding the causes of problematic pain management in sickle cell disease: Evidence that pseudoaddiction plays a more important role Than genuine analgesic dependence. Journal of Pain and Symptom Management, 27(2), 156-169.

Gil, K. M., Williams, D. A., Thompson Jr., R. J., \& Kinney, T. R. (1991). Sickle cell disease in children and adolescents: The relation of child and parent pain coping strategies to adjustment. Journal of Pediatric Psychology, 16(5), 643-663.

Gil, K. M., Williams, D. A., Thompson Jr., R. J., \& Kinney, T. R (1993). Sickle cell disease pain in children and adolescents. Journal of Pediatrics Psychology, 18(5), 621-637.

Gil, K. M, Porter, L., Ready, J., Workman, E., Sedway, J., \& Anthony, K. K. (2000). Pain in children and adolescents with sickle cell disease: An analysis of daily pain diaries. Children's Health Care, 29(2), 225-241.

Guimarães, S. S. (1999). A dor na infância. In M. M. M. Carvalho (Org.), Dor: um estudo multidisciplinar (pp. 248-264). São Paulo, SP: Summus. 
Guimarães, T. M. R., Miranda, W. L., \& Tavares, M. M. F. (2009). O cotidiano das famílias de crianças e adolescentes portadores de anemia falciforme. Revista Brasileira de Hematologia e Hemoterapia, 31(1), 9-14.

Graumlich, S. E., Powers, S. W., Byars, K. C., Schwarber, L. A., Mitchell, M. J., \& Kalinyak, K. A. (2001). Multidimensional assessment of pain in pediatric sickle cell disease. Journal of Pediatric Psycholoy, 26(4), 203-214.

Hicks, C. L., von Baeyer, C. L., Spafford, P., van Korlaar, I., \& Goodenough, B. (2001). The Faces Pain Scale (revised): Toward a common metric in pediatric pain measurement. Pain, 93,173-183.

Klein, V. C., \& Linhares, M. B. M. (2007). Temperamento, comportamento e experiência dolorosa na trajetória do desenvolvimento da criança. Paidéia, 17(36), 33-44.

Lemanek, K. L., \& Ramanalli. (2009). Sickle cell disease. In M. C. Roberts (Ed.), Handbook of pediatric psychology (pp. 303-318), London: The Guilford Press.

Lauwerier, E., Van Damme, S., Goubert, L., Paemeleire, K., Devulder, J., \& Crombez, G. (2012). To control or not? A motivational perspective on coping with pain. Acta Neurologica Belgica, 112(1), 3-7.

Lima, A. S. S. (2009). Avaliação de estratégias de coping em crianças com cancro: estudo exploratório (Dissertação de Mestrado). Mestrado Integrado em Psicologia (Secção de Psicologia Clínica e da Saúde/Núcleo Psicologia da Saúde e da Doença), Universidade de Lisboa, Portugal.

Lobo, C., Marra, V. N., \& Silva, R. M. G. (2007). Crises dolorosas na Anemia Falciforme. Revista Brasileira de Hematologia e Hemoterapia, 29(3), 247-258.

Meltzoff, J. (2001). Research strategies and variables. In Critical thinking about research: Psychology and related fields (pp. 31-48). Washington, DC: American Psychological Association.

Moraes, E. O., \& Enumo, S. R. F. (2008). Estratégias de enfrentamento da hospitalização em crianças avaliadas por instrumento informatizado. PsicoUSF, 13(2), 221-231.

Motta. A. B., \& Enumo, S. R. F. (2010). Intervenção psicológica lúdica para o enfrentamento da hospitalização em crianças com câncer. Psicologia: Teoria e Pesquisa, 26(3), 445-454.

Murta, S. G. (1999). Avaliação e manejo da dor crônica. In M. M. M. Carvalho (Org.), Dor - um estudo multidisciplinar (pp. 175-194). São Paulo: Summus. 
Mussa, C., \& Malerbi, F. E. K. (2008). O impacto da atividade lúdica sobre o bem estar de crianças hospitalizadas. Psicologia Teoria e Prática, 10(2), 83-93.

Noel, M., McMurtry, C. M., Chambers, C. T., \& McGrath, P. J. (2010). Children's memory for painful procedures: The relationship of pain. Journal of Pediatric Psychology, 35(6), 626-636.

Nonose, E. R. S. (2009). Doenças crônicas na escola: um estudo das necessidades dos alunos (Dissertação de Mestrado). Programa de Pós-Graduação em Educação. Universidade Estadual Paulista, Marilia, SP.

Palermo, T. M., \& Bayer, C. L. (2008). How to talk to parentes about recorrent and chronic pain. In G. A. Walco, K. R. Goldschneider (Eds.), Pain in children: A pratical guide for primary care (pp. 125-131). London: Humana Press.

Palermo, T. M., Eccleston, C., Lewandowski, A. S., William, A. C. C., \& Morley, S. (2011). Randomized controlled trials of psychological therapies for management of cronic pain in children and adolescents: An updated met-analytic review. Pain, 148, 387-397.

Poveda, C. L. E. C., Silva, J. A., Passareli, P., Santos, J., \& Linhares, M. B. M. (2010). Instructions for administering the Faces Pain Scale-Revised (FPS-R) in languages other than English. Pediatric Pain Sourcebook. Recuperado de: www.painsourcebook.ca

Rossato, L. M., \& Magaldi, F. M. (2006). Multidimensional tools: Application of pain quality cards in children. Revista Latino-Americana de Enfermagem, 14(5), 702-707.

Santos, A. R. R., \& Miyasaki, M. C. O. (1999). Grupo de sala de espera em ambulatório de doença falciforme. Revista Brasileira de Terapia Comportamental e Cognitiva, $1(1), 41-48$.

Sena, T. S. (2011). Sequestro esplênico agudo. Revista Baiana de Pediatria, 5(1), 66-67.

Sena, T. S., Vieira, C., \& Lyra, I. M. (2011). Fase aguda do acidente vascular encefálico na doença falciforme. Revista Baiana de Pediatria, 5(1), 54-55.

Sena, T. S., \& Tostes, M. A. (2011). Manejo da crise dolorosa na anemia falciforme. Revista Baiana de Pediatria, 5(1), 63-65.

Silva, D. G., \& Marques, I. R. (2007). Intervenções de enfermagem durante crises álgicas em portadores de anemia falciforme. Revista Brasileira de Enfermagem, 60(3), 327-330. 
Silva, J. A., \& Ribeiro-Filho, N. P. (2011). Avaliação psicofísica da percepção de dor. Psicologia USP, 22(1), 223-263.

Silva, M. C., \& Shimauti, E. L. T. (2006). Eficácia e toxicidade da hidroxiuréia em crianças com anemia falciforme. Revista Brasileira de Hematologia e Hemoterapia, 28(2), $144-148$.

Skinner, E. A., \& Wellborn, J. G. (1994). Coping during childhood and adolescence: A motivational perspective. In D. Featherman, R. Lerner \& M. Perlmutter (Eds.), Lifespan development and behavior (Vol. 12, pp. 91-133). Hillsdale, NJ: Erlbaum.

Skinner, E. A., Edge, K., Altaman, J., \& Sherwood, H. (2003). Searching for the structure of coping: A review and critique of category systems for classifying ways of coping. Pychological Bulletim, 129, 216-269.

Skinner, E. A., \& Zimmer-Gembeck, M. J. (2007). The development of coping. Annual Review of Psychology, 58, 119-144.

Thomas, V. J., Gruen, R., \& Shu, S. (2001). Cognitive-behavioural therapy for the management of sickle cell disease pain: Identification and assessment of costs. Ethnicity \& Health, 6(1), 59-67.

Tostes, M. A., Braga, J. A., Len, C. A., \& Hilário, M. O. (2008). Avaliação de dor em crianças e adolescentes portadores de anemia falciforme. Revista Ciências Médicas, 14(36), 141-147.

Tostes, M. A., Braga. J. A., \& Len, C. A. (2009). Abordagem da crise dolorosa em crianças portadoras de doença falciforme. Revista Ciências Médicas, 18(1), 47-55.

Walco, G. A., \& Dampier, C. D. (1990). Pain in children and adolescents with sickle cell disease: A descriptive study. Journal of Pediatric Psychology, 15(5), 643-658.

Van Damme, S., Crombez, G., \& Eccleston, C. (2008). Coping with pain: A motivational perspective. Pain, 139, 1-4.

Wohlheiter, K. A., \& Dahlquist, L. M. (2012). Interactive versus passive distraction for acute pain management in young children: The role of selective attention and development. Journal of Pediatric Psychology, 1-11. Recuperado de http://jpepsy. oxfordjournals.or

Recebido: $12 / 12 / 2012$

Aceito: $31 / 10 / 2013$ 